\title{
A Study on the Yield Strength of bcc Latticed Metals and Alloys
}

\author{
H. Aytekin, ${ }^{\text {a,1 }}$ G. Said, ${ }^{\mathrm{b}}$ and D. Aktaş ${ }^{\mathrm{b}}$
}

${ }^{a}$ Faculty of Technology, Metallurgy and Materials Engineering Department, Afyon Kocatepe University, Afyonkarahisar, Turkey

${ }^{\mathrm{b}}$ Engineering Faculty, Mechanical Engineering Department, Bartın University, Bartın, Turkey

1.aytekinhll@gmail.com

\section{УДК 539.4}

\section{Исследование предела текучести металлов и сплавов с ОЦК-кристалли- ческой решеткой}

\author{
Х. Айтекин ${ }^{\mathrm{a}}$, Г. Саид ${ }^{\sigma}$, Д. Акташ \\ а Афьон Коджатепс университет, Афьонкарахисар, Турция \\ ${ }^{6}$ Университет г. Бартын, Турция
}

Предложен математический подход, позволяющий теоретически прогнозировать зависимости предела текучести металлов и сплавов с ОЦК-кристаллической решеткой от температуры и скорости деформации. При этом величину предела текучести для произвольной скорости деформации можно рассчитать на основании экспериментальных данных, полученных для двух различных скоростей деформации.

Ключевые слова: металлы и сплавы с ОЦК кристаллической решеткой, предел текучести, скорость деформации, температура

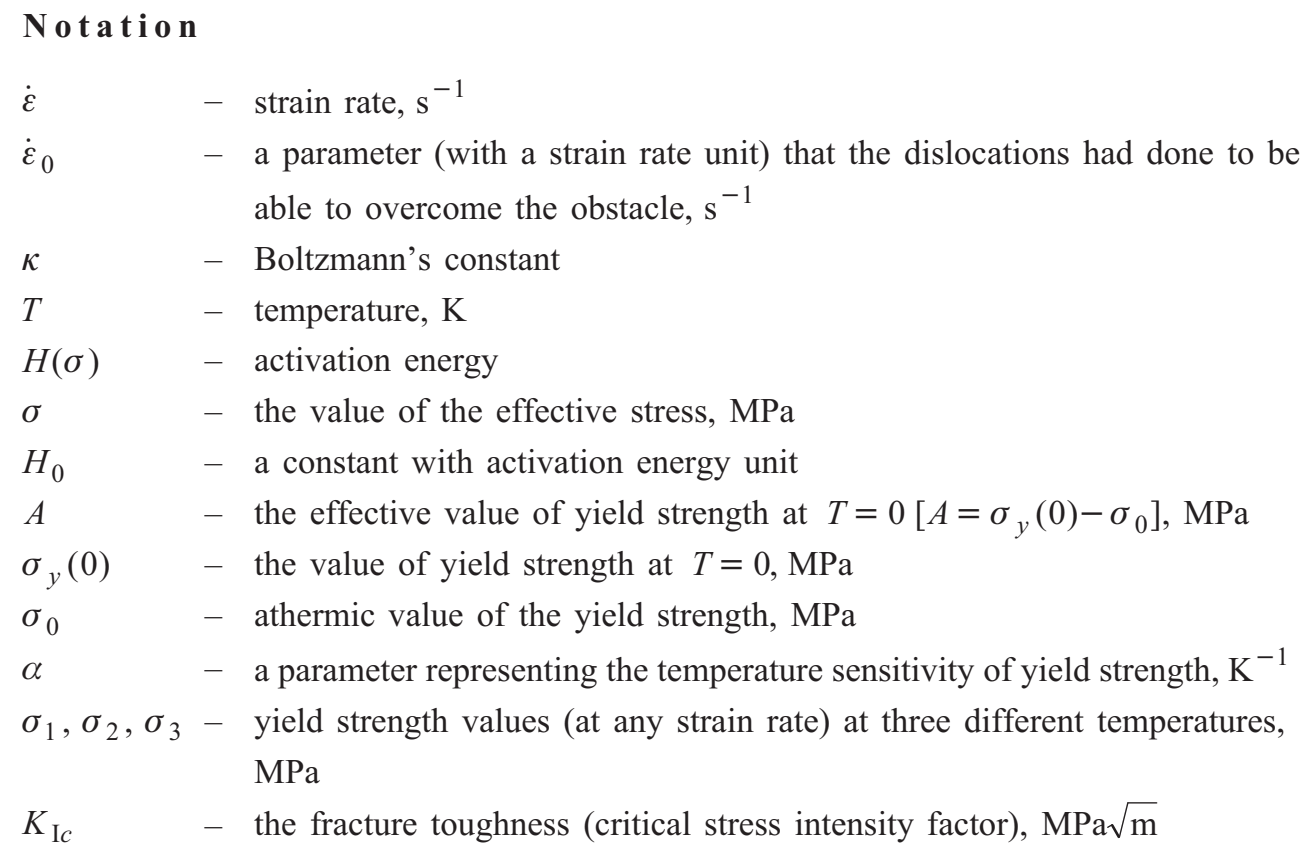


Introduction. Most machine parts used in industry are made of bcc latticed steels the yield strength of which $\sigma_{y}$ changes with temperature. The yield strength of these steels is inversely proportional to temperature (Fig. 1a). This behavior of the yield strength refers to the tendency of these steels to brittle fracture.

In the study of Said [1], a new method, based on this behavior of the yield strength, was developed to determine the fracture toughness $K_{\mathrm{Ic}}$ of bcc latticed steels. Variation of the yield strength with temperature and strain rate are shown in Fig. 1a and b, respectively.

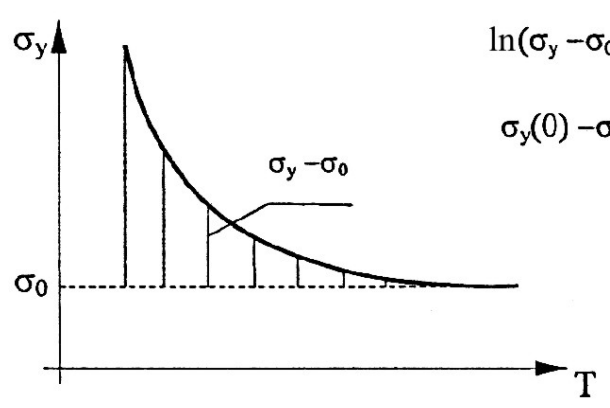

a

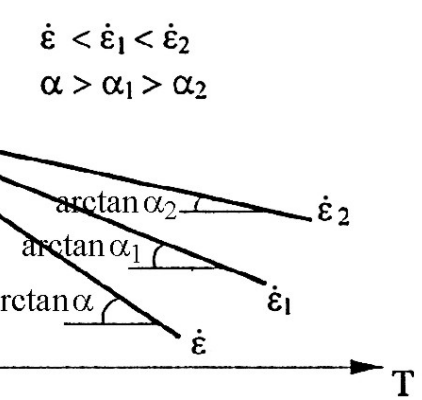

$\mathrm{b}$

Fig. 1. The change of the yield strength with temperature (a) and strain rate (b).

The yield strength variation of bcc latticed steels with temperature depicted in Fig. 1a consists of athermal, i.e., temperature-independent $\left(\sigma_{0}\right)$, and thermal activation, i.e., temperature-dependent $\left(\sigma_{y}-\sigma_{0}\right)$, parts. However, the yield strength of these steels also depends on strain rate $\dot{\varepsilon}$. As $\dot{\varepsilon}$ increases, $\sigma_{y}$ increases and therefore, the possibility of brittle fracture of machine parts made of these steels also increases.

Temperature and strain rate dependency graphs of the yield strength of bcc latticed steels are of great importance for the design of machine parts made of these steels. For this purpose, $\sigma_{y}=f(T)$ graphs should be obtained at different temperatures and strain rates with experimental results.

In this study, the aim was to theoretically determine the graphs of the change in the yield strength with temperature and strain rate at any strain rate (for example $\dot{\varepsilon}=$ $=4 \cdot 10^{-4}-1 \cdot 10^{2} \mathrm{~s}^{-1}$ range) using the data experimentally determined at two different strain rates $\left(\dot{\varepsilon}_{1}, \dot{\varepsilon}_{2}\right)$ and $T=77-293 \mathrm{~K}$ temperature range.

1. Theoretical Background. The basis of the theory proposed in this paper is described below. For dislocations to be able to move in a crystal, they have to pass through the elastic stress fields formed as a result of various obstacles and with a from near and far distance. Only the obstacles with a nearby effect can be overcome due to the help of thermal activation. Generally, the applied stress value is lower than that which is necessary for the dislocation to overcome the obstacles. Therefore, in order for the dislocation to be able to overcome the obstacle, a limited number of atoms found within the dislocation need to have the sufficient energy to be able to overcome this obstacle with thermal fluctuations (jumps).

Strain rate, temperature, and applied stress are the basic parameters in the theory of plastic deformation of metals. The thermal activation theory of plastic deformation is based on the explanation of the dislocation motion in terms of thermodynamics. Dislocation motion brings about deformation and therefore deformation is controlled by the processes which determine the dislocation motion (displacement). In the thermal activation theory of plastic deformation, the applied stress, thermal activation energy or the effect of both are taken into account in terms of dislocations overcoming obstacles. 
Conservative motion of dislocations constitutes the physical mechanism of plastic deformation of crystals at low temperatures $\left(\leq 0.2 T_{e r}, \mathrm{~K}\right)$ on the natural indentation and protrusion of the deformed lattice (various errors exist in the crystal lattice). The parameters characterizing the process of the progress through which dislocations overcome the obstacles are thermal activation of plastic deformation, activation volume and repeated attempts to overcome the obstacle. The determination of these parameters through simple mechanical experiments enables us to predict the dependency of plastic deformation properties of the material on temperature and strain rate even in more complex conditions [2].

The theoretical basis for the analysis of the results of the experiment is expressed by the following expression:

$$
\dot{\varepsilon}=\dot{\varepsilon}_{0} \exp \left[-\frac{H(\sigma)}{k T}\right] .
$$

In Eq. (1), the activation energy of the plastic deformation is expressed by the shear stress. However, in this study, the activation energy is taken as the value of the normal stress at the level of the yield strength.

In a study conducted by Yaroshevich and Rivkina [2], the model for the motion of a dislocation segment was analyzed and the following expression was obtained for the activation energy $H(\sigma)[3]$

$$
H(\sigma)=H_{0} \ln \left[\frac{\sigma(0)-\sigma_{0}}{\sigma-\sigma_{0}}\right] .
$$

When Eq. (2) is placed in Eq. (1) and some changes are made, the following expression is obtained for the thermal activation part of the yield strength

$$
\sigma_{y}-\sigma_{0}=A \exp (-\alpha T)
$$

If the logarithm of Eq. (3) is taken, then

$$
\ln \left(\sigma_{y}-\sigma_{0}\right)=\ln A-\alpha T \text {. }
$$

Equation (4) represents the line located under the angle equal to $\arctan \alpha$ in the semilogarithmic coordinate system $\left[\ln \left(\sigma_{y}-\sigma_{0}\right)-T\right]$ (Fig. 1b).

The parameter that expresses the sensitivity of the yield strength to the strain rate,

$$
\alpha=\frac{k}{H_{0}} \ln \frac{\dot{\varepsilon}_{0}}{\dot{\varepsilon}} .
$$

According to Eq. (5), as can be seen in Fig. 1b, the value of the parameter $\alpha$ decreases as the strain rate $\dot{\varepsilon}$ increases and when $\dot{\varepsilon}=\dot{\varepsilon}_{0}$, then $\alpha=0$. This means that when $\dot{\varepsilon}=\dot{\varepsilon}_{0}$, the sensitivity of the steel to the strain rate is lost. In this case, the yield strength of the steel becomes $\sigma_{y}=A$.

In order to determine the temperature change graphs of the yield strength of the bcc latticed steels at various strain rates $\left(\dot{\varepsilon} \approx 4 \cdot 10^{-4}-1 \cdot 10^{2} \mathrm{~s}^{-1}\right)$, series of experiments should be performed within the range of $T=77-293 \mathrm{~K}$ temperatures (uniaxial tensile tests of cylindrical specimens).

The functional dependence of the parameter $\alpha$ on $\dot{\varepsilon}_{0}, H_{0}$ and $\dot{\varepsilon}$ should be determined in order to reduce the number of the experiments, that is, to obtain the dependence of the parameter $\alpha$ on strain rate $[\alpha=f(\dot{\varepsilon})]$. 
To do this, let us write Eq. (5) with two strain rates $\left(\dot{\varepsilon}_{1}, \dot{\varepsilon}_{2}\right)$

(1) $\alpha_{1}=\frac{k}{H_{0}} \ln \frac{\dot{\varepsilon}_{0}}{\dot{\varepsilon}_{1}}$

$$
\left(\alpha_{2}\left\langle\alpha_{1} ; \dot{\varepsilon}_{2}\right\rangle \dot{\varepsilon}_{1}\right)
$$

(2) $\alpha_{2}=\frac{k}{H_{0}} \ln \frac{\dot{\varepsilon}_{0}}{\dot{\varepsilon}_{2}}$

$\left[\dot{\varepsilon}_{0}\right.$ is determined from (1)/(2) rate in Eq. (6)].

This means,

$$
n=\frac{\alpha_{1}}{\alpha_{2}}=\frac{\ln \dot{\varepsilon}_{0}-\ln \dot{\varepsilon}_{1}}{\ln \dot{\varepsilon}_{0}-\ln \dot{\varepsilon}_{2}} .
$$

From here

$$
\ln \dot{\varepsilon}_{0}=\frac{n \ln \dot{\varepsilon}_{2}-\ln \dot{\varepsilon}_{1}}{n-1} .
$$

If the above relation is incorporated into Eq. (6), then

$$
H_{0}=\frac{k}{\alpha_{1}}\left(\ln \dot{\varepsilon}_{0}-\ln \dot{\varepsilon}_{1}\right)=\left(\frac{k}{\alpha_{1}} \frac{n \ln \dot{\varepsilon}_{2}-\ln \dot{\varepsilon}_{1}}{n-1}-\ln \dot{\varepsilon}_{1}\right) .
$$

From here

$$
H_{0}=\frac{k}{\alpha_{1}} \frac{n}{n-1} \ln \frac{\dot{\varepsilon}_{2}}{\dot{\varepsilon}_{1}}
$$

$\alpha$ value for any strain rate,

$$
\alpha=\frac{k}{H_{0}} \ln \frac{\dot{\varepsilon}_{0}}{\dot{\varepsilon}}=\frac{k \alpha_{1}(n-1)}{k n \ln \frac{\dot{\varepsilon}_{2}}{\dot{\varepsilon}_{1}}}\left(\frac{n \ln \dot{\varepsilon}_{2}-\ln \dot{\varepsilon}_{1}}{n-1}-\ln \dot{\varepsilon}\right) .
$$

From here

$$
\alpha=\frac{\alpha_{1}}{n \ln \frac{\dot{\varepsilon}_{2}}{\dot{\varepsilon}_{1}}}\left(n \ln \frac{\dot{\varepsilon}_{2}}{\dot{\varepsilon}}-\ln \frac{\dot{\varepsilon}_{1}}{\dot{\varepsilon}}\right) .
$$

In Eq. (9), $\alpha=\alpha_{1}$ for $\dot{\varepsilon}=\dot{\varepsilon}_{1}$ and $\alpha=\alpha_{2}$ for $\dot{\varepsilon}=\dot{\varepsilon}_{2}$.

Equation (9) shows the relationship between the strain rate $\dot{\varepsilon}$ and the parameter $\alpha$, which expresses the sensitivity of the yield strength to the strain rate.

2. Materials. Two different steels with bcc structure are investigated. The areas of use of these steels are given in Table 1, and their chemical compositions are given in Table 2.

As can be seen from Table 2, these are low-carbon steels. In addition, 15Kh2NMFA is a low-alloy steel, while M16C is an unalloyed steel.

3. Results and Discussion. The value of $\alpha$ should be calculated, in order to determine the relationship between the strain rate $\dot{\varepsilon}$ and the parameter $\alpha$, which expresses the sensitivity of the yield strength to the strain rate according to Eq. (9). Experimental determination of the $\alpha$ value is as follows. 
$\mathrm{T}$ a b 1 e 1

Usage Area of the Steels

\begin{tabular}{|c|c||}
\hline Steel & Usage area of the steels \\
\hline $15 \mathrm{Kh} 2 \mathrm{NMFA}$ & Reactor body of nuclear energy central \\
\hline M16C & Construction of bridges and other engineering structures \\
\hline
\end{tabular}

T a b 1 e 2

Chemical Composition of the Steels

\begin{tabular}{|c|c|c|c|c|c|c|c|c|c|c||}
\hline Steel & $\mathrm{C}$ & $\mathrm{Mn}$ & $\mathrm{Si}$ & $\mathrm{Cu}$ & $\mathrm{Ni}$ & $\mathrm{Cr}$ & $\mathrm{Mo}$ & $\mathrm{P}$ & $\mathrm{S}$ & $\mathrm{Fe}$ \\
\hline 15Kh2NMFA & 0.16 & 0.40 & 0.23 & 0.04 & 1.65 & 1.78 & 0.64 & 0.008 & 0.006 & Balance \\
\hline $\mathrm{M} 16 \mathrm{C}$ & 0.17 & 0.46 & 0.15 & 0.17 & 0.09 & 0.05 & - & 0.017 & 0.029 & Balance \\
\hline
\end{tabular}

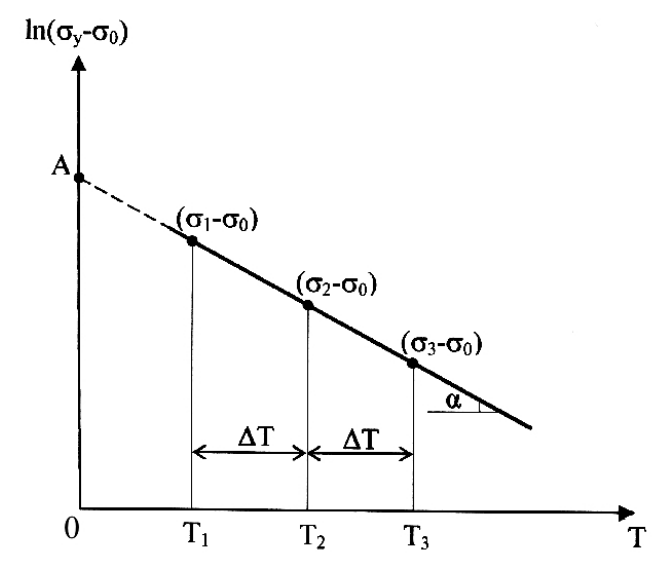

Fig. 2. Schematic representation of $\ln \left(\sigma_{y}-\sigma_{0}\right)-T$ graph.

First, the value of $\sigma_{0}$ in Eq. (3), which represents the dependence of the yield strength on temperature and strain rate, should be determined. For this purpose, three temperatures $\left(T_{1}, T_{2}\right.$, and $\left.T_{3}\right)$ are selected in the $\ln \left(\sigma_{y}-\sigma_{0}\right)-T$ graph (see Fig. 2) derived from any strain rate $\left(T_{1}-T_{2}=T_{2}-T_{3}=\Delta T\right)$ and then yield strengths are determined at these temperatures.

The value of $\sigma_{0}$ is obtained from the ratio given below,

$$
\frac{\ln \left(\sigma_{1}-\sigma_{0}\right)}{\ln \left(\sigma_{2}-\sigma_{0}\right)}=\frac{\ln \left(\sigma_{2}-\sigma_{0}\right)}{\ln \left(\sigma_{3}-\sigma_{0}\right)} .
$$

From here

$$
\frac{\sigma_{1}-\sigma_{0}}{\sigma_{2}-\sigma_{0}}=\frac{\sigma_{2}-\sigma_{0}}{\sigma_{3}-\sigma_{0}}
$$

when Eq. (11) is solved according to $\sigma_{0}$,

$$
\sigma_{0}=\frac{\sigma_{2}^{2}-\sigma_{1} \sigma_{3}}{2 \sigma_{2}-\left(\sigma_{1}+\sigma_{3}\right)} .
$$

The athermal component $\left(\sigma_{0}\right)$ of the yield strength is independent of the strain rate. 
The value of $\sigma_{0}$ can also be obtained by the graphical-and-analytical method. To do this, as shown in Fig. 3a, a few tangent points are chosen from $\sigma_{y}=f(T)$ graph and a line is obtained in the $\partial \sigma_{y} / \partial T-\sigma_{y}$ coordinate system (Fig. 3b). The point where this line crosses the $\sigma_{y}$ axis is equal to $\sigma_{0}$. Since the value $\sigma_{0}$ is, in theory, the value of the $\sigma_{y}$ at $T=\infty$ temperature, $\sigma_{y}=\sigma_{0}$ in the $\partial \sigma_{y} / \partial T-\sigma_{y}$ coordinate system at $\partial \sigma_{y} / \partial T=0$.

The value of $\sigma_{0}$ for the M16C steel was assessed as $122 \mathrm{MPa}$ according to Eq. (12) and as $120 \mathrm{MPa}$ according to Fig. 3 [4].

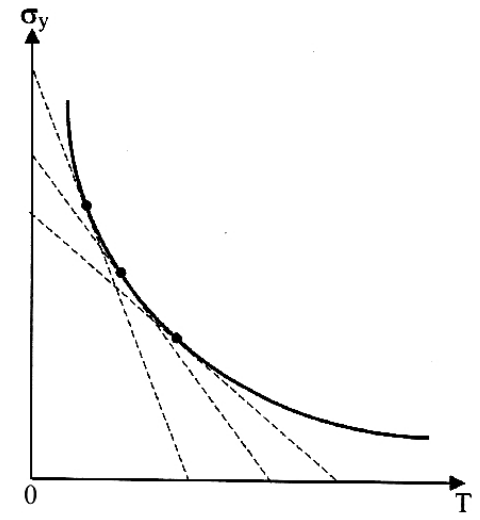

a

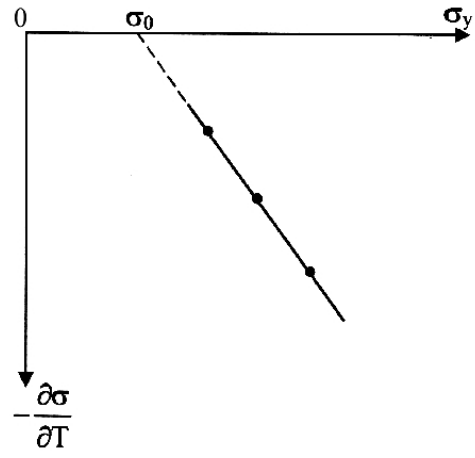

b

Fig. 3. Schematic representation of the yield strength variation with temperature (a) and determination of the value $\sigma_{0}(\mathrm{~b})$.

Finally, the $\alpha$ and $A$ values can be calculated from the following expressions:

$$
\begin{gathered}
\alpha=\frac{1}{\Delta T} \ln \left(\frac{\sigma_{1}-\sigma_{0}}{\sigma_{2}-\sigma_{0}}\right), \\
A=\left(\sigma_{1}-\sigma_{0}\right) e^{\alpha T_{1}}=\left(\sigma_{2}-\sigma_{0}\right) e^{\alpha T_{2}}=\left(\sigma_{3}-\sigma_{0}\right) e^{\alpha T_{3}} .
\end{gathered}
$$

As a result, the dependence of the yield strength on temperature and strain rate can be evaluated by means of the parameters $\alpha, \sigma_{0}$, and $A=\sigma(0)-\sigma_{0}$, according to Eq. (3).

Let us numerically calculate the $\alpha=f(\dot{\varepsilon})$ relation for the 15Kh2NMFA steel.

The experimental results for this steel are given in Table 3 [5].

Thus,

$$
n=\frac{\alpha_{1}}{\alpha_{2}}=1.805, \quad \frac{\dot{\varepsilon}_{2}}{\dot{\varepsilon}_{1}}=10^{6}
$$

If these data are substituted into Eq. (9), we get

$$
\alpha=\frac{1.26 \cdot 10^{6}}{1.805 \ln \frac{200}{2 \cdot 10^{-4}}}\left(1.805 \ln \frac{200}{\dot{\varepsilon}}-\ln \frac{2 \cdot 10^{-4}}{\dot{\varepsilon}}\right) .
$$

The obtained relationship between $\alpha$ and $\dot{\varepsilon}$ is shown in Table 4 .

As can be seen in Table 4 , as the strain rate $\dot{\varepsilon}$ increases, the parameter $\alpha$, which expresses the sensitivity of the steel to the strain rate, decreases. 
$\mathrm{T}$ a b 1 e 3

Experimental Results of the 15Kh2NMFA Steel [5]

\begin{tabular}{|c|c|c|c|c|c||}
\hline \multirow{2}{*}{ Steel } & Experiment & \multicolumn{2}{|c|}{$\dot{\varepsilon}, \mathrm{s}^{-1}$} & \multicolumn{2}{c|}{$\alpha, \mathrm{K}^{-1}$} \\
\hline \multirow{2}{*}{ 15Kh2NMFA } & 1 & $\dot{\varepsilon}_{1}$ & $2 \cdot 10^{-4}$ & $\alpha_{1}$ & $1.26 \cdot 10^{-2}$ \\
\cline { 2 - 6 } & 2 & $\dot{\varepsilon}_{2}$ & 200 & $\alpha_{2}$ & $6.98 \cdot 10^{-3}$ \\
\hline
\end{tabular}

$\mathrm{T}$ a b 1 e 4

Relationship between $\alpha$ and $\dot{\varepsilon}$

\begin{tabular}{|c|c|c|c||}
\hline$\dot{\varepsilon}, \mathrm{s}^{-1}$ & $1.805 \ln \frac{200}{\dot{\varepsilon}}$ & $\ln \frac{2 \cdot 10^{-4}}{\dot{\varepsilon}}$ & $\alpha \cdot 10^{2}, \mathrm{~K}^{-1}$ \\
\hline $10^{-4}$ & 26.188 & 0.693 & 1.275 \\
\hline $10^{-3}$ & 22.030 & 1.609 & 1.182 \\
\hline $10^{-2}$ & 17.875 & 3.912 & 1.090 \\
\hline $10^{-1}$ & 13.720 & 6.215 & 0.997 \\
\hline $10^{0}$ & 9.563 & 8.517 & 0.904 \\
\hline $10^{1}$ & 5.407 & 10.820 & 0.811 \\
\hline $10^{2}$ & 1.245 & 13.122 & 0.718 \\
\hline
\end{tabular}

Conclusions. It is shown that the value of parameter $\alpha$, which represents the temperature sensitivity of the yield strength, can be predicted for any bcc latticed steel via Eq. (9) for different strain rates without conducting an experiment, provided $\alpha_{1}$ and $\alpha_{2}$ values of this steel at two different strain rates $\left(\dot{\varepsilon}_{1}\right.$ and $\left.\dot{\varepsilon}_{2}\right)$ are known.

If the value of $\alpha$ is known, the graph of yield strength variation with temperature (at any strain rate) can be obtained via Eq. (3).

\section{Резюме}

Запропоновано математичний підхід, що дозволяє теоретично прогнозувати залежність границі плинності металів і сплавів з ОЦК-кристалічною граткою від температури і швидкості деформації. При цьому величину границі плинності для довільної швидкості деформації можна розрахувати на основі експериментальних даних, отриманих для різних швидкостей деформації.

1. G. Said, "Study on ASTM E399 and ASTM E1921 standards," Fatigue Fract. Eng. Mater. Struct., 29, 606-614 (2006).

2. A. Ya. Krasovskii, Metal Brittleness at Low Temperatures [in Russian], Naukova Dumka, Kiev (1980).

3. V. D. Yaroshevich and D. G. Rivkina, "The thermoactivation character of plastically deformation of metals," Fiz. Tverd. Tela, No. 3, 464-477 (1970).

4. L. A. Kopelman, Resistance against Brittle Fracture in Welded Sections [in Russian], Machinostroenie, Moscow (1978).

5. A. Ya. Krasovskii and V. N. Krasiko, Fracture Toughness of Steels of Main Lines [in Russian], Naukova Dumka, Kiev (1990).

Received 11. 08. 2014 